DIGITALCOMMONS

@WAYNESTATE —
Michigan Journal of Counseling:

Research, Theory and Practice

Volume 31 | Issue 2

Article 4

10-1-2003

\title{
The Use of the Parental Alliance Measure with Women Parenting Children with Disabilities
}

\author{
Abeer Abdo \\ Washington Division of Vocational Rehabilitation \\ Jerry Fischer \\ University of Idaho, jfischer@uidaho.edu \\ Dan Kmitta \\ University of Idaho
}

Follow this and additional works at: https://digitalcommons.wayne.edu/mijoc

\section{Recommended Citation}

Abdo, A., Fischer, J., \& Kmitta, D. (2003). The Use of the Parental Alliance Measure with Women Parenting Children with Disabilities, Dimensions of Counseling, 31(2), 17-24. doi:10.22237/mijoc/1064966580

This Article is brought to you for free and open access by the Open Access Journals at DigitalCommons@WayneState. It has been accepted for inclusion in Michigan Journal of Counseling: Research, Theory and Practice by an authorized editor of DigitalCommons@WayneState. 


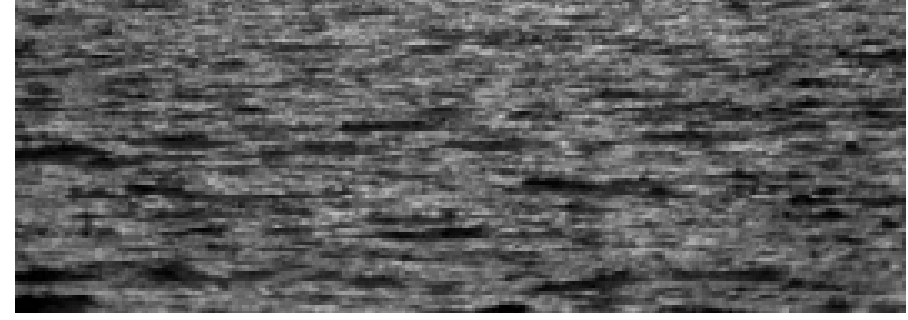

\section{The Use of the Parental Alliance Measure with Women Parenting Children with Disabilities}

\author{
Abeer Abdo, Ph.D. \\ Washington Division of Vocational Rehabilitation
}

\section{Jerry Fischer, Ph.D.}

University of Idaho

\section{Dan Kmitta, Ph.D.}

University of Idaho

Correspondence regarding this article can be directed to Jerome

M. Fischer, ACTE, P.O. Box 3083, University of Idaho, Moscow,

ID 83844 or to jfischer@uidaho.edu
This study investigated the use of the Parental Alliance Measure (PAM) with women parenting children with disabilities. A total of 117 women who parent children with disabilities participated in the study. Using factor analysis, the same two factors were identified for this study as the original standardization group for the PAM. Factor 1 for this study was defined by 17 items and was labeled Communication and Teamwork for Mothers. Factor 2 had 3 items and was labeled Feels Respected by the Other Parent. Results suggested the PAM was robust for use with women who parent children with disabilities. The PAM may be used with families to understand parenting dynamics, develop strategies, and increase involvement in the therapeutic process. arents' reactions to the birth of a child with a disability and the subsequent care, nurturing, education, and vocational development are complicated (Rolland, 1984; Wood, 1995). The typical parent, while looking ahead to the birth of a child fantasizes about and forms images of the expected infant. The parents' expectations may include achievement such as success in a societal role, a profession, or proficiency at some activity. When the parents are informed that their child has a disability, the loss of the fantasized child and the discrepancy between these expectations and reality precipitate a crisis reaction accompanied with feelings of grief and loss (Marinelli \& Dell Orto, 1991). These reactions may have a traumatic effect on the entire family, which may predispose the child and other members of the family to problems of adjustment throughout childhood, 
adolescence, young adulthood and beyond in many cases (Ziolko, 1991).

A child's cognitive, behavioral, and emotional abilities affect his or her relationship with each member of the family (Leinbaugh, 1997). In addition, demands of child-care can influence each parent's level of cooperation and involvement to meet the child's needs.

Early research on parent- child interactions focused on both effects of parental behaviors that influence the child and child behaviors that influence parents (Brody, 1956; Broussard \& Hartner, 1970; White, 1971; Thomas et al., 1963). Recent research has considered the effect of the parenting alliance and cooperation on the child's behavior (Weissman \& Cohen, 1985) as well as the child's behavior on the parental alliance (Abidin \& Brunner, 1995).

Many instruments have been developed to measure factors of marital and family functioning including adjustment (Epstein, Baldwin \& Bishop, 1983; Spanier, 1976; Spanier \& Filsinger, 1983); assets (Olson, Portner \& Lavee., 1985); feelings (Lowman, 1980); communication (Bienvenu, 1978); satisfaction (Roach, Frazier \& Bowden, 1981; Snyder, 1981); stability (Booth \& Edwards, 1983); trust (Larzelere \& Huston, 1980); expectancies (Notarius \& Vanzetti, 1983); coping strategies (McCubbin, Larsen, \& Olson, 1985); strength of family ties (Bardis, 1975); and intimacy ( Waring \& Reddon, 1983). Whereas these instruments provide a measure of general influences on parenting, they do not provide a specific measure of the parents' working relationship with regard to child rearing.

The concept of parenting alliance was created by Weissman \& Cohen (1985) to describe the part of the marital relationship that is concerned with parenthood and child rearing. According to Weissman \& Cohen (1985), a parental alliance would be considered constructive when the following conditions are met: "(1) each parent is invested in the child, (2) each parent values the other parent's involvement with the child, (3) each parent respects the judgments of the other parent, and (4) each parent desires to communicate with the other" (Weissman \& Cohen, 1985, p.25). In other words, a parenting alliance reflects the parents' ability to cooperate with each other in meeting the needs of the child (Abidin \& Konold, 1999). Parents involved in meeting the needs of a child with a disability may have similar or more intense demands placed on their parenting alliance. n other words, a

parenting alliance

reflects the parents'

ability to cooperate

with each other in

meeting the needs

of the child (Abidin

\& Konold, 1999).

Parents involved in

meeting the needs

of a child with a

disability may have

similar or more

intense demands

placed on their

parenting alliance.

A measure of the degree of parental alliance would provide important information for counselors working with children and adolescents with disabilities and their parents. The importance of working with families has been recognized in counseling literature (Kosciulek \& Pichette, 1996; Marsh, 1992; Smith \& Godfrey, 1995). Counselors need to understand the parental dynamics of families when working with school age clients (Sutton, 1985).

Furthermore, family-centered involvement has resulted in increased client participation in counseling programs (Kelly \& Lambert, 1992).

\section{Parenting Alliance Measure}

This instrument was developed by Abidin \& Konold (1999) to assess the working relationship of parents in child rearing. Research on parenting alliance grew out of studies of the effects of conflict in marriage on child outcomes (Emery, 1988). Abidin developed an instrument to focus on those aspects of the marital relationship that relate directly to parenting. He recognized that measures of marital satisfaction or adjustment were not sufficient in measuring parenting behavior. He hypothesized that both parents can be involved in the parenting role and yet not be very satisfied with their personal relationship with each other (Abidin, 1992). PAM originated when the name of the instrument was changed from the Parenting Alliance Inventory (PAI). The PAI contained the identical items, instructions, and scoring as the current PAM; therefore, research results reported for PAI can be generalized to the PAM. PAM has been standardized for use with parents of children ages 1 year to 19 years. The normative sample approximates the 1997 United States census projections with regard to several population characteristics. As a result, the PAM is applicable to parents in a wide variety of demographic contexts (Abidin \& Konold, 1999).

Although the normative sample included parents of children with disabilities, there were not sufficient numbers in this category. In addition, current studies have not researched the use of the measure with parents of different types of children's disabilities other than Attention-Deficit/Hyperactivity Disorder, OppositionalDefiant Disorder and Conduct Disorder (Abidin \& Konold, 1999). Therefore, the purpose of this study was to investigate the use of the Parental Alliance Measure (PAM) with parents of children with disabilities. The research question for this study was 
1. Is the Parental Alliance Measure a useful instrument for parents of children with disabilities?

\section{Methodology}

\section{Participants}

Participants in this study were primary caregivers of children with disabilities who were contacted through a parent support groups' coordinator of a Northwest state or attended an annual state conference for parents of children with disabilities. For the purposes of this study, the primary caregivers generally, were those selfidentified as biological parent, grandparent, stepparent, adoptive parent, or foster parent. This study used data generated by primary caregivers that provided information about the family demographics and responded to the Parenting Alliance Measure (PAM). Participation was voluntary. Participants of this study were 180 parents of children with disabilities age 1 year to 19 years. Sixty-three participants were contacted through a mailing to coordinators of parents support groups, and 117 were contacted at a state conference.

Of these surveys $23 \%(n=41)$ were unusable because the participants did not have a child with disability, or their child was older than 19 years old or they did not include their gender when completing the surveys. Of the139 usable surveys, male participants were $16 \%(\mathrm{n}=22)$, of the sample and female participants were $84 \%(\mathrm{n}=117)$, of the sample. Proportionally, the males were not represented adequately which would make their data insufficient for computing statistics and were not included in this study. Therefore, the study retained the female respondents $(n=117)$ for reporting results.

Of the participants, $90.6 \%$ reported they were white, 5.1 $\%$ Latino, and $4.3 \%$ American Indian. Nineteen percent reported having a disability. Ages of the participants ranged from 21 to 58 with $68 \%$ between 26 and 45 . A total of $59 \%$ had a college degree or higher, $56 \%$ lived in a rural area, and $57 \%$ had an income of $\$ 25,000$ a year or more. Eighty-one percent were living with their parental partner, with the range of years participants were in a parental partnership being between 1 and $36.51 \%$ were in their partnership between 6 and 15 years.

All participants were parents of children with disabilities, and $86 \%$ reported being the biological parent of the child with a disability. Thirty-nine percent reported that their first-born child had a disability, and $47 \%$ indicated it was their second or the third child that had a disability. A total of $62 \%$ of the children with disabilities were male. Fortynine percent of the children of the participants were between the ages of 4 and 11, and $61 \%$ had acquired the disability at birth. Twenty-five percent of the children with disabilities had a primary and a secondary disability.
For primary disabilities, developmental disabilities accounted for $36 \%$, physical disabilities for $35 \%$, and psychological disabilities $29 \%$. For those participants reporting a child with a secondary disability, psychological disabilities accounted for $11 \%$, developmental 10\%, and physical 3\%. When asked what percentage of the caregiving they provided their child, the average response was $69 \%$. When asked what percentage of caregiving their partner provided, the average response was $34 \%$. The two questions were not linked to allow for caregiving provided by members outside of the parental partnership. However, the combined estimates for both questions exceeded $100 \%$.

\section{Instrumentation}

The Parenting Alliance Measure has 20 items measured on a handscorable test form (Abin \& Konold, 1999). Parents respond to items using a 5-point rating scale where $1=$ Strongly Disagree with the statement and $5=$ Strongly Agree with the statement. Items contained in PAM measure if each parent: 1) is invested in the child (e.g., "My child's other parent pays a great deal of attention to our child," 2) values the other parent's involvement with the child (e.g., My child's other parent enjoys being alone with our child," 3 ) respects the judgments of the other parent (e.g., "I feel good about my child's other parent's judgment about what is right for your child," 4) desires to communicate with the other parent (e.g., "When there is a problem with our child, we work out a good solution together." PAM requires a thirdgrade reading level and can be completed in less than 10 minutes. The higher the PAM score, the stronger the parenting alliance and the more respectful and coordinated the transactions are between the parenting partners. For interpretation, PAM scores equal to or greater than the twentieth percentile are considered normal, marginal parenting alliance scores would range between the nineteenth and fifteenth percentile, problematic parenting alliance scores would range between the fourteenth and sixth percentile, and dysfunctional parenting alliance would be equal to or less than the fifth percentile.

PAM was standardized on 1,224 parents of children and adolescents in proportion to the 1997 United States Census (Abin \& Konold, 1999). A test-retest reliability coefficient of .97 was computed for PAM with a second test administration of 4 to 6 weeks later. An internal consistency coefficient alpha of .95 was computed.

The rational-empirical approach to the development of PAM (Abin \& Konold, 1999) provided content validity for the measure using the following steps: 1) a review of the literature to identify the major variables associated with parenting relationships (80 items identified); 2) item refinement based on professional judgments of 
knowledgeable clinicians and researchers (five family therapists and five psychologists) as well as suggestions and feedback from parents (reduced to 30 items) ; and 3) further refinement based on statistical analysis of field tested items (final 20 items).

Criterion-related validity for the PAM was established by correlating the measure with the Stress Index for Parents of Adolescents (Sheras, Abidin, \& Konold 1998) with correlations ranging from -.55 for mothers and .68 for fathers. Correlations with the Family Adaptability and Cohesion Evaluation Scales III (Olson, Portner, \& Lavee, 1985) yielded a low of .35 with mothers on the Adaptability subscale and high of .75 with fathers on the Cohesion subscale. Correlations with the Dyadic Adjustment Scale (Spanier, 1976) yielded a low of .52 with mothers and a high of .75 with fathers.

Construct validity for the PAM was established by a number of comparisons of known groups. PAM measured significant differences between married and separated/divorced parents, parents from normative and clinical samples, families who have utilized mental health services, and families whose adolescents have had a history or delinquent behavior. Discriminant validity was established by Bearss and Eyberg (1998). The study identified that PAM made a unique contribution to the prediction of children's adjustment over and above the quality of marital relationship (Locke \& Wallace, 1959).

\section{Data Analysis}

Means and standard deviations of participants' responses to the PAM were computed to determine the range of scores for each item. To determine if the PAM is effective in measuring the parental alliance of parents of children with disabilities, responses to the PAM were analyzed by principle component factorial analysis. A comparison was made between the results of the factor analysis from this study to the factor analysis of the normative group used in the development of the test.

Generally many popular rules for principle component factor analysis state that sample size be determined as a function of the number of variables being analyzed, ranging anywhere from two subjects per variable to 20 subjects per variable. However, Stevens (2002), based on empirical studies, posits that the most important factors are component saturation and absolute sample size rather than the ratio of subjects to variables. Furthermore, he stated that reasonable and reliable conclusions can be drawn from studies with at least three loadings above .80 , regardless of sample size. The principle component factor analysis of this study met Stevens' criteria.
Table 1

Means and Standard Deviations of PAM Items

\begin{tabular}{lllll} 
PAM ltems & N & Mean & $\begin{array}{l}\text { Standard } \\
\text { Deviation }\end{array}$ \\
\hline $\begin{array}{l}\text { 1. My child's other parent enioys } \\
\text { being alone with our child }\end{array}$ & 117 & 4.11 & 1.13 \\
\hline $\begin{array}{l}\text { 2. During pregnancy, my child's other parent expressed } \\
\text { confidence in my ability to be a good parent }\end{array}$ & 117 & 4.30 & .95 \\
\hline $\begin{array}{l}\text { 3. When there is a problem with our child, } \\
\text { we work out a good solution together }\end{array}$ & 117 & 3.80 & 1.17 \\
\hline $\begin{array}{l}\text { 4. My child's other parent and I communicate } \\
\text { well about our child }\end{array}$ & 117 & 3.82 & 1.19 \\
\hline
\end{tabular}

5. My child's other parent is willing to make personal sacrifices to help take care of our child

$\begin{array}{lll}117 & 3.91 & 1.25\end{array}$

6. Talking to my child's other parent about our child is something I look forward to

$\begin{array}{lll}117 & 3.70 & 1.15\end{array}$

7. My child's other parent pays a great deal of attention to our child

$\begin{array}{lll}117 & 3.88 & 1.21\end{array}$

8. My child's other parent and I agree on what our $\begin{array}{llll}\text { child should and should not be permitted to do } & 117 & 3.79 & 1.14\end{array}$

9. I feel close to my child's other parent when I see him or her play with our child $\begin{array}{lll}117 & 4.21 \quad 1.07\end{array}$

10. My child's other parent knows how to handle children well

$\begin{array}{lll}117 & 3.80 & 1.23\end{array}$

11. My child's other parent and I are a good team

$\begin{array}{lll}117 & 3.91 \quad 1.18\end{array}$

12. My child's other parent makes my job of being a parent easier $\begin{array}{lll}117 & 4.34 & .77\end{array}$

13. I believe my child's other parent is a good parent $\quad 117 \quad 4.17 \quad 1.00$

14. My child's other parent makes my job of being a parent easier

$\begin{array}{lll}117 & 3.78 & 1.22\end{array}$

15. My child's other parent sees our child in the same way I do

$117 \quad 3.41 \quad 1.20$

16. My child's other parent and I would basically describe our child in the same way

$\begin{array}{lll}117 & 3.54 & 1.18\end{array}$

17. If our child needs to be punished, my child's other parent and I usually agree on the type of punishment

$\begin{array}{lll}117 & 3.58 & 1.10\end{array}$

18. I feel good about my child's other parent's judgment about what is right for our child $\begin{array}{lll}117 & 3.81 & 1.09\end{array}$

19. My child's other parent tells me I am a good parent $117 \quad 4.14 \quad .88$

20. My child's other parent and I have the same goals for our child

$\begin{array}{lll}117 & 3.93 & 1.11\end{array}$




\section{Results}

Means and Standard deviations of participant responses to the PAM can be seen in Table 1 .

PAM item 12, "my child's other parent believes I am a good parent," had the highest mean $(\mathrm{M}=4.34, \mathrm{SD}=.77)$. Conversely PAM item 15, "my child's other parent sees our child in the same way I do," had the lowest mean (M $=3.41, \mathrm{SD}=1.20$ ).

A comparison of the results between the factor analysis from this study and the factory analysis of the normative group can be seen in Table 2 .

For both groups of the normative group of women and the women participants of this study, a two factor solution was identified: factor 1 for this study was defined by 17 items and was labeled Communication and Teamwork for Mothers; factor 2 had 3 items and was labeled Feels Respected by the Other Parent. Total variance accounted for was very similar for the normative group and current study, $69.9 \%$ and $69.05 \%$ respectively. Each factor identified the same items.

\section{Discussion}

Perhaps the most important result is the PAM is deemed robust for mothers of children with disabilities participating in this study. Previous research focused on marital satisfaction or adjustment and fell short in ascertaining the parental alliance component of parental partnerships, especially, parents of children with disabilities. However, this study demonstrates the viability of the PAM for measuring parental alliance for women with children with disabilities.

Parenting behaviors have been related to developmental deficiencies and childhood problems (Abidin, 1992). The parental alliance as conceptualized by Weissman and Cohen (1985) describes the mutual concern of the parenting partners with the child's well being. This aspect of the alliance is crucial given that research has

demonstrated that the ability of partners to work together is a predictor of the quality of caregiving provided the child (Nihira, Mink \& Meyers, 1985). Furthermore, the parent alliance is a factor in partner problem-solving and conflict resolution. Partners who value and respect each other have demonstrated an ability to communicate effectively with each other. Consequently, research has shown that parents who work well together to meet challenging obstacles can provide a warm and nurturing environment for their children (Howes \& Markman, 1989). Lastly, research has indicated that the parenting alliance affects the self-concept and conflict resolution skills of children (Weissman \& Cohen, 1985).
Table 2

A Comparison Between the Normative Group and the Current Study of the Two-Factor Solution for Women: Principal Component Analysis

\begin{tabular}{|c|c|c|c|c|}
\hline \multicolumn{3}{|c|}{$\begin{array}{c}\text { * Principal component } \\
\text { analysis/ Normative Group }\end{array}$} & \multicolumn{2}{|c|}{$\begin{array}{l}\text { ** Principal component } \\
\text { analysis/ Current study }\end{array}$} \\
\hline PAM item number & CT-M & FROP & CT-M & FROP \\
\hline 5 & 0.84 & 0.21 & 0.865 & 0.00475 \\
\hline 14 & 0.83 & 0.31 & 0.835 & 0.168 \\
\hline 10 & 0.83 & 0.28 & 0.868 & -0.0862 \\
\hline 13 & 0.82 & 0.36 & 0.826 & 0.203 \\
\hline 18 & 0.81 & 0.34 & 0.88 & -0.131 \\
\hline 11 & 0.81 & 0.33 & 0.865 & 0.0766 \\
\hline 7 & 0.81 & 0.25 & 0.818 & 0.0562 \\
\hline 4 & 0.78 & 0.41 & 0.835 & -0.1979 \\
\hline 6 & 0.76 & 0.33 & 0.839 & -0.1257 \\
\hline 1 & 0.73 & 0.35 & 0.756 & -0.0596 \\
\hline 3 & 0.71 & 0.43 & 0.845 & -0.143 \\
\hline 9 & 0.7 & 0.34 & 0.818 & 0.0985 \\
\hline 17 & 0.66 & 0.41 & 0.77 & -0.244 \\
\hline 15 & 0.65 & 0.47 & 0.854 & -0.179 \\
\hline 8 & 0.64 & 0.46 & 0.715 & -0.244 \\
\hline 20 & 0.62 & 0.45 & 0.741 & -0.0344 \\
\hline 16 & 0.61 & 0.46 & 0.819 & -0.279 \\
\hline 12 & 0.34 & 0.81 & 0.551 & 0.681 \\
\hline 2 & 0.2 & 0.8 & 0.457 & 0.603 \\
\hline 19 & 0.38 & 0.76 & 0.663 & 0.364 \\
\hline Eigenvalue & 12.9 & 1.1 & 12.4 & 1.38 \\
\hline$\%$ variance & 64.5 & 5.4 & 62.14 & 6.9 \\
\hline Cum $\%$ variance & 64.5 & 69.9 & 62.14 & 69.05 \\
\hline
\end{tabular}

Note, ${ }^{\star} \mathrm{N}=879$ for the Normative Group and ${ }^{\star \star} \mathrm{N}=117$ for the current study.

CT-M = Communication and Teamwork=Mothers Scale; FROP= Feels Respected by other Parent. Factor loadings in bold type are ( .36 and indicate items loading on their intended factor. 
Emerging from the birth and maturation of a child with a disability within the family system are a number of issues that are significant because they are related to the mental health of the child with a disability (Miller, 1995). The foremost complex developmental process the family undertakes is the adaptation to disability by parents, the child with the disability, siblings, and people significant to the family. Livneh (1986a, 1986b) proposed a model of adaptation with five phases: initial impact, defense mobilization, initial realization, retaliation, and reintegration. Research has shown partial confirmation of the model for family members and other significant people to the family (Antonak \& Livneh, 1991). Counselors can impact the process by coaching and assisting the family through the five stages, along with intervening in any impediments to the process. Additionally, this process could be aided by an accurate assessment of parenting obstacles via the PAM.

Another important issue for the family is the successful completion of developmental tasks by the child with a disability (Eisenberg, Sutkin, \& Jansen, 1984).

Accordingly, adaptation to disability affects the manner in which the child develops. Although all of the tasks are crucial, in particular the tasks related to adolescence may uniquely challenge the family which includes separation from family, identification with peers, and management of independence. These milestones may be affected by the child's functional limitations such as mobility barriers, speech problems, and opportunities for social activities. Parenting discord would compound this stressful time in a family's lifecycle. Hence, the assistance of a counselor may help the family through these trials.

An important use of PAM would be implementing strategies born from its results to meet the challenge of making meaning of separation or divorce within the family. There are differing reports concerning the divorce rates among families with children with disabilities. Studies indicate that there is a higher level of stress among partners with children with disabilities, and this stress is a catalyst for separation and divorce (Ziolko, 1991). The PAM was constructed and validated with the concept that partners do not have to be satisfied with each other but can still come together to continue to provide appropriate parenting. The counselor's task would be to help facilitate the process of separation or divorce and yet maintain the parenting alliance.
Participants in this research reported perceiving a high degree of respect from the other parent. On the other hand, they reported to a lesser degree that their parenting partner sees their child with a disability the same way that they do. This suggests a possible discrepancy among the partners in the way that they experience their child with a disability. This discrepancy may result in a conflict of emotions for the partners (Bristor, 1991) and consequently impede the developmental process of the child. Since communication is vital when it comes to parenting a child with a disability given the medical, educational, and vocational issues that may develop, counselors may want to focus on the parents establishing good communication skills.

Traditionally women have been the primary caregivers in families (McGoldrick, Anderson, \& Walsh, 1989). This holds true in the results of this study, with women providing $69 \%$ of the caregiving to the child with a disability. This dynamic may contribute to the strength of the parental alliance between partners. However, it may also be a source of distress for the family. If counselors encounter a situation where the inequality in caregiving is distressing a family, they may seek resources from family, friends, and community groups to help provide respite care for the child and assist in lessening the caregiving load of the primary caregiver.

Finding community resources to assist parents of children with disabilities to overcome the challenges they face with their families may be a daunting task for a counselor. Parent educational and support groups may contribute some assistance. However, it is evident that few resources exist for families, and counselors might appreciate a community resource for families that can more fully provide family counseling services. To meet this challenge, counselors may build coalitions among community human service providers who also need counseling and education resources for the families they assist. Community mental health, schools, hospitals, health and welfare programs, developmental disabilities programs, religious organizations, women's centers, and planned parenthood are examples of community agencies who may come together to provide counseling and other services to families. The coalitions could then seek funding for services from state and local governments, civic organizations, or local charities. 
The PAM can be used by counselors working with families to facilitate a number of therapeutic interventions. However, further study on these complex issues is warranted. The sample used in this research was limited to women parenting children with disabilities, and respondents resided in a Northwestern state. The unique characteristics of the study participants included their being predominantly white, in a rural setting, with a high level of education. Therefore, caution should be used when generalizing the results of this research to other populations. Before generalized usage, the PAM should be validated for use with parents of adult children with disabilities beyond the age of 19.Given the preponderance of women primary caregivers, it is recommended that future research be conducted with men parenting children with disabilities, as well as with diverse families from different ethnic groups. While Brunner (1991) found that PAM scores were able to significantly predict child behaviors as rated by teachers, implying a relationship between child development and parental alliance, it would be critical to study the relationship comprehensively.

This study suggests that PAM may be used by counselors to facilitate an understanding among partners of their parenting dynamics which may affect the developmental gains of the child or adolescent with a disability. Based on the results of the PAM, counselors could develop specific strategies to increase the communication and teamwork by parents and enhancing feelings of respect by each partner for the other which would achieve a stronger parental alliance. Counselors could use such interventions with the family to facilitate greater therapeutic gains (Kelly \& Lambert, 1992). It is important to remember that while assessing the parenting alliance is a part of the process, the primary work where counselors can be significantly helpful is in facilitating the resolution of those issues.

\section{References}

Abidin, R.R. (1992). The determinants of parenting behavior. Journal of Clinical Child Psychology, 21(4), 407-412.

Abidin, R.R., \& Brunner, J.F. (1995). Parenting alliance measure: Professional manual. Florida: Psychological Assessment Resources, Inc..

Abidin, R.R., \& Konold,T.R. (1999). Parenting alliance measure: Professional manual. Florida: Psychological Assessment Resources, Inc.

Antonak, R.F., \& Livneh, H. (1991). A hierarchy of reactions to disability. International Journal of Rehabilitation Research, 14, 13-24.

Bearss, K.E., \& Eyberg, S.M. (1998). A test of the parenting alliance theory. Early Education and Development, 9, 179-185.

Bienvenu, M.J., Sr. (1978). A counselor's guide to accompany a Marital Communication Inventory. Saluda, NC: Family Life.

Booth, A., \& Edwards, J. (1983). Measuring marital instability. Journal of Marriage and the Family, 45, 387-393.

Bardis, P.D. (1975). The Borromean family. Social Science, 50, 144-158.

Bristor, M.W. (1991). The birth of a handicapped child: A wholistic model for grieving. In R.P. Marinelli and A.E. Dell Orto (Eds.), The Psychological and Social Impact of Disability (3rd. ed.) (pp. 59-70). New York: Springer Publishing Co.

Brody, S. (1956). Patterns of mothering: Maternal influence during infancy. New York: International Universities Press, Inc.

Broussard, E.R., \& Hartner, M.S.S. (1970). Maternal perception of the neonate as related to development. Child Psychiatry and Human Development, 1, 16-25.

Brunner, J.F. (1991). The development of the Parenting Alliance Inventory. Unpublished doctoral dissertation, University of Virginia, Charlottesville.

Eisenberg, M.G., Sutkin, L.C., \& Jansen, M.A. (1984). Chronic illness and disability through the life span. New York: Springer Publishing Co.

Emery, R.E. (1982). Interparental conflict and the children of discord and divorce. Psychological Bulletin, 92, 310-330.

Epstein, N., Baldwin, L., \& Bishop, S. (1983). The McMaster Family Assessment Device. Journal of Marital and Family Therapy, 9, 171-180.

Eyberg, S.M., \& Pincus, D. (1999). The Eyberg Child Behavior Inventory and Sutter-Eyberg Student Behavior Inventory-Revised professional manual. Odessa, FL: Psychological Assessment Resources.

Howes, P., \& Markman, H.J. (1989). Marital quality and child functioning: A longitudinal investigation. Child Development, 60, 1044-1051.

Kelly, S., \& Lambert, S. (1992). Family support in rehabilitation: A review of research, 1980-1990. Rehabilitation Counseling Bulletin, 36, 98-119.

Kosciulek, J. \& Pichette, E. (1996). Adaptation concerns of families of people with head injury. Journal of Applied Rehabilitation Counseling, 27, 8-13.

Larzelere, R., \& Huston, T. (1980). The Dyadic Trust Scale: Toward understanding interpersonal trust in close relationships. Journal of Marriage and the Family, 43, 595-604.

Leinbaugh, T.C. (1997). The effect of a sixteen-hour workshop on school counselors'awareness, knowledge, and skills, and attitudes toward students with disabilities. Moscow, ID: University of Idaho.

Livneh, H. (1986a). A unified approach to existing models of adaptation to disability: Part I: A model of adaptation. Journal for Applied Rehabilitation Counseling, 17(1), 5-16. 
Livneh, H. (1986b). A unified approach to existing models of adaptation to disability: Part II: Intervention strategies. Journal for Applied Rehabilitation Counseling, 17(2), 6-10..

Locke, H.J., \& Wallace, K.M. (1959). Short marital adjustment and prediction tests: Their reliability and validity. Marriage and Family Living, 21, 251-255.

Lowman, J.C. (1980). Measurement of family affective structure. Journal of Personality Assessment, 44, 130-141.

McCubbin, H., Larsen, A., \& Olson, D. (1985). F-COPES: Family Crisis Oriented Personal Evaluation Scale. In D.H. Olson, H.I. McCubbin, H.L. Barnes, A.S. Larsen, M. Muxen, \& M. Wilson (Eds.), Family Inventories (Revised). St. Paul: Family Social Science, University of Minnesota.

McGoldrick, M., Anderson, C.M., \& Walsh, F. (1989). Women in families: A framework for family therapy. New York: Norton.

Marinelli, R.P., \& Dell Orto, A.E., (1991). The psychological and social impact of disability (3rd ed.). New York: Springer Publishing Co.

Marsh, D. (1992). Families and mental illness; New directions in professional practice. New York: Praeger.

Miller, B. (1995). Promoting healthy function and development in chronically ill children: A primary care approach. Family Systems Medicine, 13(2), 187-200.

Nihira, K., Mink, I.T., \& Meyers, C.E. (1985). Home environment and development of slow-learning adolescents: Reciprocal relations. Developmental Psychology, 21, 784-794.

Notarius, C.I., U Vanzetti, N.A. (1983). The Marital Agendas Protocol. In E. Filsinger (Ed.), Marriage and family assessment: A sourcebook for family therapy. Beverly Hills: Sage.

Olson, D.H., \& Larsen, A.S., \& McCubbin, H.I. (1985). Family Strengths. In D.H.Olson, H.I. McCubbin, H.L. Barnes, A.S. Larsen, M. Muxen, \& M. Wilson (Eds.), Family Inventories (rev.ed.). St. Paul: Family Social Science, University of Minnesota.

Olson, D., Portner, J., \& Lavee, Y. (1985). Family Adaptability and Cohesion Evaluations Scales III. St. Paul: University of Minnesota.

Roach, R.J., Frazier, L.P., \& Bowden, S.R. (1981). The Marital Satisfaction Scale: Development of a measure for intervention research. Journal of Marriage and the Family, 21, 251-255.
Rolland, J.S., (1984). Toward a psychosocial typology of chronic lifethreatening illness. Family Systems Medicine, 2, 245-262.

Sheras, P.L., Abidin, R.R., \& Konold, T.R., (1998). Stress Index for Parents of Adolescents professional manual. Odessa, F:: Psychological Assessment Resources.

Snyder, D.K. (1981). Marital Satisfaction Inventory (MSI) manual. Los Angeles: Western Psychological Services.

Spanier, G.B. (1976). Measuring dyadic adjustment: New scales for assessing the quality of marriage and similar dyads. Journal of Marriage and Family, 38, 15-28.

Spanier, G.B., \& Filsinger, E. (1983). The Dyadic Adjustment Scale. In E.Filsinger (Ed.), Marriage and family assessment. Beverly Hills: Sage.

Smith, L.M., \& Godfrey, H.P.D. (1995). Family support programs and rehabilitation: A cognitive-behavioral approach to traumatic brain injury. New York: Plenum.

Stevens, J.P. (2002). Applied multivariate statistics for the social sciences (4th ed.). Mahwah, New Jersey: Laurence Erlbaum Associates Inc.

Sutton, J. (1985). The need for family involvement in client rehabilitation. Journal of Applied Rehabilitation Counseling, 4, 68-75.

Thomas, A., Chess, S., Birch, H., Hertizidg, M., \& Korn, S. (1963). Behavioral individuality in early childhood. London: University of London Press.

Waring, E.M., \& Reddon, J. (1983). The measurement of intimacy in marriage: The Waring Questionnaire. Journal of Clinical Psychology, 39, 53-57.

Weissman, S.H., \& Cohen, R.S. (1985). The parenting alliance and adolescence. Adolescent Psychiatry, 12, 24-45.

White, B.L. (1971). An analysis of excellent early education practices: Preliminary report. Interchange: A Journal of Educational Studies, 2(2), 86-87.

Wood, B. (1995). A developmental biopsychosocial approach to the treatment of chronic illness in children and adolescents. In R.H. Mikesell, D.D., Lusterman, \& S.H. McDaniel (eds.), Integrating family therapy: Handbook of family psychology and systems theory. Washington DC: American Psychological Association.

Zoilko, M.E. (1991). Counseling parents of children with disabilities: A review of literature and implications for practice. Journal of Rehabilitation, 57(2), 29-34. 